\title{
An optimized SPE-LC-MS/MS method for antibiotics residue analysis in ground, surface and treated water samples by response surface methodology- central composite design
}

Roya Mirzaei ${ }^{1}$, Masoud Yunesiann ${ }^{2,3}$, Simin Nasseri ${ }^{1,2}$, Mitra Gholami $^{4}$, Esfandiyar Jalilzadeh ${ }^{5}$, Shahram Shoeibi ${ }^{6}$, Hooshang Shafieyan Bidshahi ${ }^{6}$ and Alireza Mesdaghinia ${ }^{1,2^{*}}$ (D)

\begin{abstract}
Background: Antibiotic residues are being constantly identified in environmental waters at low concentration. Growing concern has been expressed over the adverse environmental and human health effects even at low concentration. Hence, it is crucial to develop a multi-residues analytical method for antibiotics to generate a considerable dataset which are necessary in the assessment of aquatic toxicity of environmental waters for aquatic organisms and human health. This work aimed to develop a reliable and sensitive multi-residue method based on high performance liquid chromatography coupled with quadrupole-linear ion trap tandem mass spectrometry (HPLC-MS-MS). The method was optimized and validated for simultaneous determination of four classes of antibiotics including, $\beta$-lactam, macrolide, fluoroquinolone and nitro-imidazole in treated, ground and surface water matrices.

Methods: In order to optimize the solid phase extraction process, main parameters influencing the extraction process including, $\mathrm{pH}$, the volume of elution solvent and the amount of $\mathrm{Na}_{4} \mathrm{EDTA}$ were evaluated. The optimization of extraction process was carried out by response surface methodology using central composite design. Analysis of variance was performed for nine target antibiotics using response surface methodology.

(Continued on next page)
\end{abstract}

\footnotetext{
* Correspondence: mesdaghinia@sina.tums.ac.ir

${ }^{1}$ Center for Water Quality Research (CWQR), Institute for Environmental

Research (IER), Tehran University of Medical Sciences, 8th floor, Gol Building,

North Karegar St., Enghelab Sq, Tehran, Iran

${ }^{2}$ Department of Environmental Health Engineering, School of Public Health,

Tehran University of Medical Sciences, Tehran, Iran

Full list of author information is available at the end of the article
} 
(Continued from previous page)

Results: The extraction recoveries were found to be sensitive to the independent variables of $\mathrm{pH}$, the volume of elution solvent and the amount of $\mathrm{Na}_{4}$ EDTA. The extraction process was $\mathrm{pH}$-dependent and $\mathrm{pH}$ was a significant model term in the extraction process of all target antibiotics. Method validation was performed in optimum operation conditions in which the recoveries were obtained in the range of 50-117\% for seven antibiotics in spiked treated and ground water samples and for six antibiotics in spiked river water samples. Method validation parameters in terms of method detection limit were obtained in the range of $1-10 \mathrm{ng} / \mathrm{L}$ in treated water, $0.8-10 \mathrm{ng} / \mathrm{L}$ in the ground water and $0.8-25 \mathrm{ng} / \mathrm{L}$ in river water, linearity varied from 0.95 to 0.99 and repeatability in term of relative standard deviation values was achieved less than $10 \%$ with the exception for metronidazole and ceftriaxone. The developed method was applied to the analysis of target antibiotics in treated, ground and surface water samples.

Conclusions: Target antibiotics were analyzed in different water matrices including treated, ground and river water. Seven out of nine antibiotics were detected in Kan River and Firozabad Ditch water samples, although none of them were detected in treated water and ground water samples.

Keywords: LC/MS/MS, Solid phase extraction, Response surface methodology, $\beta$-lactam antibiotics, Cephalosporins

\section{Background}

Antibiotics are one of the most important groups of pharmaceuticals used in human and veterinary medicine extensively. Concerns have been growing worldwide about their occurrence in environmental waters. Considering that they are metabolized to some extent after administration, unmetabolized active compounds are excreted in urine (generally $55-80 \%$ ) and feces as a mixture of metabolites or conjugated compounds [1]. Accordingly, they can enter water bodies through effluent of urban wastewater treatment plants (UWWTP), hospital and pharmaceutical treatment plants due to their removal inefficiently by conventional systems $[2,3]$. Furthermore, the release of effluent into water bodies, which can serve as a source for drinking water production facilities, is truly significant because the quality of people's life who live in downstream areas can be affected by antibiotic residues [4-6]. Thus, it is significant to establish a sensitive and reliable analytical method to determine the amount of multi-residue of antibiotics or other pharmaceutical active compounds (PhACs) at the concentration range of $\mathrm{ng} / \mathrm{L}$ and low $\mu \mathrm{g} / \mathrm{L}$ in water bodies.

Many researchers have developed methods to find a board range of antibiotics in various water matrices [7-13]. All these methods are based on liquid chromatography coupled with tandem mass spectrometry. In these methodologies, many parameters related to chromatographic conditions such as the ionization response of electrospray ionization mass spectrometry (ESI-MS), and the extraction process which has been optimized individually in different levels. However, the interaction between variables hadn't been taken into account statistically.

Therefore, a systematic approach such as an experimental design to optimize the extraction process is highly essential. Furthermore, diverse physicochemical properties of pharmaceutical compounds, such as antibiotics, make them display different extraction efficiencies after extraction process and analysis. These variables include $\mathrm{pH}$, the amount of $\mathrm{Na}_{4}$ EDTA and the volume of elution solvent. Traditional procedures of optimization like (one-variableat-a-time) are time-consuming and costly, while they fail to show interactions among the parameters. On the other hand, many researchers worked under different conditions, including neutral and acidic condition, various amounts chelating agent and different volumes of elution solvent. Hence similar and contrasting recoveries have been reported $[8,14,15]$. In order to optimize significant parameters in an extraction process, multivariate optimization strategies such as Response Surface Methodology (RSM) based on experimental design was applied as a widely used approach for evaluating the main effects and variable interactions within at least a number of runs $[16,17]$. RSM, which is based on quadratic polynomial equation, is considered as the most useful method to predict the optimum parameters in sample preparation [16].

Since six out of nine target antibiotics in this study were $\beta$-lactam and cephalosporin, the physicochemical properties and chromatographic behavior of $\beta$-lactam and cephalosporin have been particularly emphasized in this optimization method. According to previous studies, $\beta$-lactam antibiotics (BLs) are widely used due to their anti-microbial activities against gram-positive and gramnegative bacteria. Moreover their therapeutic and preventive properties, these compounds have been widely used as growth promoters in livestock animals [5]. The identification of BL compounds has been reported by a few studies in different water matrices, including wastewater treatment plant effluent $[8,18]$ and hospital wastewater [15], as well as ground, surface and drinking water $[12,14,19,20]$. However, these compounds are considered to be unstable in water matrices due to their chemical structures, so there are many restrictions to their simultaneous analysis through multi-residue 
methodologies. In addition, optimum conditions for their analysis could not be achieved and thus low recoveries were obtained for $\beta$-lactam antibiotics, including amoxicillin and penicillin $[8,21]$.

In present work, a reliable extraction method was developed for simultaneous analysis of two $\beta$-lactam antibiotics (amoxicillin and penicillin G), three cephalosporins (cefixime, cephalexin, and ceftriaxone), two macrolides (azithromycin, erythromycin), one nitro-imidazole (metronidazole), and one fluoroquinolone (ciprofloxacin) in HPLC grade water. The effects of the variables (amount of $\mathrm{Na}_{4}$ EDTA, $\mathrm{pH}$ and the volume of elution solvent) were investigated and optimized using the Central Composite Design (CCD) combined with Response Surface Methodology (RSM), followed by the Desirability Function (DF) in order to maximize the criteria of the response. Then in optimum conditions, the method was validated in treated, ground and surface water. Finally, the optimized method was applied to natural water samples.

\section{Methods}

\section{Chemicals and samples}

All antibiotic compounds including amoxicillin and penicillin G, cephalexin, ceftriaxone, cefixime, ciprofloxacin, azithromycin, erythromycin, metronidazole were of high purity grade $(>99 \%)$ and purchased from SigmaAldrich (Steinham, Germany) which are listed in Table 1. All solvents used, including the HPLC grade methanol $(\mathrm{MeOH})$, acetonitrile $(\mathrm{ACN}), \mathrm{HPLC}$ grade water, hydrochloric acid 37\% and formic acid 98\% were purchased from Merck (Darmstadt, Germany). Tetrasodium Ethylenediaminetetraacetate $\left(\mathrm{Na}_{4} \mathrm{EDTA}\right)$ was obtained from Sigma-Aldrich (Steinham, Germany). Nitrogen for drying was of high purity grade (>99/9998\%) and was supplied by Tehran Gas Co. (Tehran, Iran). Isotopically labeled compounds used as internal standards were ciprofloxacin-d8, azithromycin-d3, metronidazole- $\mathrm{d} 4$, and cefuroxime-d3, which were purchased from Santa Cruz Biotechnology (California, US) (Table 1). Oasis HLB cartridges $(6 \mathrm{~mL}, 500 \mathrm{mg})$ were supplied by Waters (Milford, USA). Glass fiber filters (GF/F, pore size $1 \mu \mathrm{m}$ ) and nylon membrane filters $(0.45 \mu \mathrm{m})$ were supplied by Merck Millipore (Darmstadt, Germany).

\section{Sample collection}

One-third of total water consumption in Tehran was supplied by ground water resources. The water withdrawn from all groundwater wells, after quality control, is directed to reservoirs. After disinfection, the water is transferred to the distribution and consumption network. Thirteen water wells representing different districts of Tehran were selected randomly. At each site, water samples were collected as close to the wellhead as possible before chlorination and after the field parameters were stabilized (electrical conductivity, temperature, $\mathrm{pH}$, dissolved oxygen) in the volume flow. Thirteen drinking water wells were sampled, one grab sample in each sampling event. A total of 39 water well samples were collected during the sampling campaign.

Raw water and treated water samples were collected from five different drinking water treatment plants (DWTPs) in Tehran. They were major drinking water suppliers in Tehran during three sampling campaigns on June 13, 2016 (wet season), July 9, 2016 (dry season), and August 2, 2016 (dry season). Two rivers (Kan River and Firozabad Ditch) in Tehran province river basin were the subjects of the study. Along the way, domestic and industrial wastewater is released into the stream, which can cause chemical and microbiological contamination in agricultural fields and gardens which are irrigated by this creek in Varamin and Ray areas in the south of Tehran. Two sampling sites were selected on the rivers. River water samples were collected from each

Table 1 Target antibiotics organized by their therapeutical groups, structures, molecular weight (MW), PKa values and their assigned internal standard with their characteristics

\begin{tabular}{|c|c|c|c|c|c|c|c|}
\hline Chemical Groups & compound & $\begin{array}{l}\text { Chemical } \\
\text { formula }\end{array}$ & MW & PKa & $\begin{array}{l}\text { Corresponding } \\
\text { internal standard }\end{array}$ & $\begin{array}{l}\text { CAT number of } \\
\text { internal standard }\end{array}$ & $\begin{array}{l}\text { Chemical formula for } \\
\text { internal standards }\end{array}$ \\
\hline \multirow[t]{2}{*}{ B-lactam } & Amoxicillin & $\mathrm{C} 16 \mathrm{H} 19 \mathrm{~N} 3 \mathrm{O} 5 \mathrm{~S}$ & $365.4 \mathrm{~g} / \mathrm{mol}$ & 3.32 & Cefuroxime-d3 & sc-217,864 & $\mathrm{C} 16 \mathrm{H} 13 \mathrm{D} 3 \mathrm{~N} 4 \mathrm{O} 8 \mathrm{~S}$ \\
\hline & Penicillin G & $\mathrm{C} 16 \mathrm{H} 18 \mathrm{~N} 2 \mathrm{O} 4 \mathrm{~S}$ & $334.4 \mathrm{~g} / \mathrm{mol}$ & 2.74 & Cefuroxime-d3 & sc- 217,864 & $\mathrm{C} 16 \mathrm{H} 13 \mathrm{D} 3 \mathrm{~N} 4 \mathrm{O} 8 \mathrm{~S}$ \\
\hline \multirow[t]{3}{*}{ Cephalosporin } & Cephalexin & $\mathrm{C} 16 \mathrm{H} 17 \mathrm{~N} 3 \mathrm{O} 4 \mathrm{~S}$ & $347.39 \mathrm{~g} / \mathrm{mol}$ & 4.5 & Cefuroxime-d3 & sc- 217,864 & $\mathrm{C} 16 \mathrm{H} 13 \mathrm{D} 3 \mathrm{~N} 4 \mathrm{O} 8 \mathrm{~S}$ \\
\hline & Ceftriaxone & $\mathrm{C} 18 \mathrm{H} 18 \mathrm{~N} 8 \mathrm{O} 7 \mathrm{S3}$ & $554.58 \mathrm{~g} / \mathrm{mol}$ & 3.19 & Cefuroxime-d3 & sc- 217,864 & $\mathrm{C} 16 \mathrm{H} 13 \mathrm{D} 3 \mathrm{~N} 4 \mathrm{O} 8 \mathrm{~S}$ \\
\hline & cefixime & $\mathrm{C} 16 \mathrm{H} 15 \mathrm{~N} 5 \mathrm{O} 7 \mathrm{~S} 2$ & $453.452 \mathrm{~g} / \mathrm{mol}$ & 3.45 & Cefuroxime-d3 & sc- 217,864 & $\mathrm{C} 16 \mathrm{H} 13 \mathrm{D} 3 \mathrm{~N} 4 \mathrm{O} 8 \mathrm{~S}$ \\
\hline Fluoroquinolones & Ciprofloxacin & $\mathrm{C} 17 \mathrm{H} 18 \mathrm{FN} 3 \mathrm{O} 3$ & $331.346 \mathrm{~g} / \mathrm{mol}$ & 5.76 & Ciprofloxacin-d8 & sc-217,902 & $\mathrm{C} 17 \mathrm{H} 10 \mathrm{D} 8 \mathrm{FN} 3 \mathrm{O} 3 \cdot \mathrm{HCl}$ \\
\hline \multirow[t]{2}{*}{ Macrolide } & Azithromycin & $\mathrm{C} 38 \mathrm{H} 72 \mathrm{~N} 2 \mathrm{O} 12$ & $748.984 \mathrm{~g} / \mathrm{mol}$ & 8.74 & Azithromycin-d3 & sc- 217,686 & C38H69D3N2O12 \\
\hline & Erythromycin & $\mathrm{C} 37 \mathrm{H} 67 \mathrm{NO} 13$ & $733.93 \mathrm{~g} / \mathrm{mol}$ & 8.88 & Azithromycin-d3 & sc- 217,686 & C38H69D3N2O12 \\
\hline $\begin{array}{l}\text { Nitro imidazole } \\
\text { antibiotics }\end{array}$ & Metronidazole & $\mathrm{C} 6 \mathrm{H} 9 \mathrm{~N} 3 \mathrm{O} 3$ & $171.15 \mathrm{~g} / \mathrm{mol}$ & 15.44 & Metronidazole-d4 & sc- 217,686 & $\mathrm{C} 6 \mathrm{H} 5 \mathrm{D} 4 \mathrm{~N} 3 \mathrm{O} 3$ \\
\hline
\end{tabular}


sampling site in duplicate on each sampling event. One liter bottles (polypropylene containers) were used for taking grab samples. Sodium thiosulfate $(20 \mathrm{mg} / \mathrm{L})$ was added to the treated water sample bottles as a quenching agent [22]. All samples were carried to the library in a cool box at $4{ }^{\circ} \mathrm{C}$ within $6-12 \mathrm{~h}$.

\section{Preparation of standard solutions and samples}

Stock standard solutions were prepared individually in a concentration of $1 \mathrm{mg} / \mathrm{mL}$, by dissolving $10 \mathrm{mg}$ of solid reference of each standard in $10 \mathrm{~mL}$ of proper solvent. Penicillin and cephalosporins were dissolved in HPLC grade water because of their stability in HPLC water [8]. Fluoroquinolone antibiotics including ciprofloxacin take a long time to dissolve in pure methanol, so the compound was dissolved in $\mathrm{MeOH} /$ HPLC water $(50: 50, v / \mathrm{v})$ with having $0.2 \%$ hydrochloric acid [22]. The rest of the target analytes were dissolved in methanol. Stock standard solutions were stored at $-20{ }^{\circ} \mathrm{C}$ and they were renewed monthly due to their instability [8]. Fresh stock standard solutions for penicillin and cephalosporin were prepared monthly and stock standard solution for the rest of compounds were prepared every three months. Afterward, working standard solutions were prepared in $\mathrm{MeOH} / \mathrm{HPLC}$ water $(50: 50, v / \mathrm{v})$ in gradient dilution and they were refreshed before each run. A mixture of isotopically labeled internal standards was prepared in methanol and further dilution was also prepared in $\mathrm{MeOH} / \mathrm{HPLC}$ water (50:50, v/v).

Three kinds of samples were prepared, the first ones were samples for optimization procedure, Individual standard solutions of antibiotics at a concentration of $1 \mathrm{mg} / \mathrm{mL}$ were prepared in appropriate solvents and then a mixture working standard solution of antibiotics at a concentration of $1 \mu \mathrm{g} / \mathrm{mL}$ was prepared in $\mathrm{MeOH} / \mathrm{HPLC}$ water (50:50, v: v). Afterward, the significant extraction parameters were studied and optimized by spiking $80 \mathrm{ng} / \mathrm{L}$ of the mixture solution of antibiotics in $100 \mathrm{~mL}$ of ultrapure water. The recoveries of antibiotics are presented in Table S1 (see Additional file 1). After optimal conditions were obtained, the second parts of samples were prepared to construct the linear rang $500 \mathrm{~mL}$ of ground, treated and river water samples were spiked by stock standard solution of each antibiotic individually in the range of concentration $0.5-500 \mathrm{ng} / \mathrm{L}$ and fixed amount of the internal standard mixture in the concentration of $80 \mathrm{ng} / \mathrm{L}$ then extracted by solid phase extraction. Finally, the third ones were the samples which prepared for method validation. $500 \mathrm{~mL}$ of ground, treated and river water samples were spiked by stock standard solution of a mixture of antibiotic at a concentration of $100 \mathrm{ng} / \mathrm{L}$ then extracted and analyzed.

\section{Solid phase extraction and the preparation of calibration curve}

Samples $(500 \mathrm{~mL})$ were collected in polypropylene containers, which had been pre-rinsed with ultrapure water. Before sampling of chlorinated water, for chlorine quenching, Sodium thiosulfate was added to chlorinated water samples at a concentration of $20 \mathrm{mg} / \mathrm{L}$ [23]. Next, the samples were passed through $1 \mu \mathrm{m}$ glass-fiber filters and followed by $0.45 \mu \mathrm{m}$ nylon membrane filters. $\mathrm{Na}_{4}$ EDTA (375 mg) was added to all samples as a chelating agent to prevent antibiotics from forming complexes with metallic ions [24]. Then filtered samples $\mathrm{pH}$ was adjusted to 3 using hydrochloric acid. Oasis HLB cartridges were selected as SPE sorbent, based on preliminary experiments in other studies and prior knowledge from the literature [8, 24-26].

Water samples were extracted with the hydrophilic/ lipophilic balanced Oasis HLB $\left(500 \mathrm{mg}, 6 \mathrm{~cm}^{3}\right)$ for all the matrices in question [8]. The HLB cartridges were conditioned by $10 \mathrm{~mL}$ of $\mathrm{MeOH}$ followed by $10 \mathrm{~mL}$ of HPLC water, which was acidified at $\mathrm{pH} 2.5$ by hydrochloric acid. Both methanol and water were passed through cartridges at a flow rate of $2 \mathrm{~mL} / \mathrm{min}$. After that, $500 \mathrm{~mL}$ of river water, treated water and ground water samples were passed through the cartridge at a flow rate of $1-2 \mathrm{~mL} / \mathrm{min}$. After preconcentration of the samples, $5 \mathrm{~mL}$ HPLC water was loaded onto the cartridges at a flow rate of $2 \mathrm{~mL} / \mathrm{min}$. The excess water was removed by vacuuming the cartridges for $30 \mathrm{~min}$. Then the analytes were eluted by passing $6 \mathrm{~mL}$ methanol through the cartridges at a flow rate of $1 \mathrm{~mL} / \mathrm{min}$ with the help of gravity in a $10 \mathrm{~mL}$ vial. Next, the extract was evaporated to dryness under a gentle stream of nitrogen at $30{ }^{\circ} \mathrm{C}$ and finally it was reconstituted with $500 \mu \mathrm{L}$ of mobile phase $(0.1 \%$ formic acid in $\mathrm{MeOH} / \mathrm{HPLC}$ grade water $(50: 50, v / v)) .20 \mu \mathrm{L}$ of the reconstituted solution was injected into HPLC-ESI-(QqLIT) MS/MS. The linear range was determined by spiking ground water, treated water and river water in the concentration range of $0.5-500 \mathrm{ng} / \mathrm{L}$ and fixed amount of the internal standard mixture in the concentration of $80 \mathrm{ng} / \mathrm{L}$. Calibration curves were plotted by the ratio of each antibiotic peak area to peak area of its corresponding internal standard. Regression coefficient (R2) values ranging, varied from 0.95 to 0.99 , to a concentration point ranging from 0.5 to $500 \mathrm{ng} / \mathrm{L}$, depending on the target antibiotics. One calibration standards were analyzed repeatedly after every 12 samples in order to check the signal stability. 
High-performance liquid chromatography-tandem mass spectrometry

Chromatographic separations were carried out using an Agilent Ultra High Performance liquid chromatography system (1260 HPLC system), equipped with Micro Vacuum Degasser, Binary pump 600 bar, automated injection system using a Zorbax-eclipse XDB-C18 $(100 \mathrm{~mm} \times 4.6 \mathrm{~mm}, 3.5 \mu \mathrm{m})$ column with guard injection $20 \mu \mathrm{L}$ and oven temperature was $25{ }^{\circ} \mathrm{C}$. The optimum separation conditions were composed of solvent A: HPLC water acidified by adding formic acid at $0.1 \%$, and solvent $\mathrm{B}$ : methanol acidified at $0.1 \%$ by adding formic acid at a flow rate of $0.8 \mathrm{ml} / \mathrm{min}$. The gradient elution was presented in Table 2.

The tandem mass analysis was performed by a 3200 QTRAP hybrid triple quadrupole linear ion trap mass spectrometer (Applied Biosystems, Foster City, CA, USA) equipped with a turbo Ion Spray source. The temperature of the electrospray source was $400{ }^{\circ} \mathrm{C}$. Ion Spry Voltage (IS) was $5500 \mathrm{~V}$. Curtain gas (CUR) was $10 \mathrm{psi}$ and ion source gas pressures (GS1) and (GS2) both of them were 50 psi. MS parameters which dependent to compounds includes (declustering potential (DP), collision energy (CE) and collision cell (CXP)) which were optimized by infusion of individual standard solutions of each compound at concentrations of $2 \mathrm{mg} /$ L. Mass spectrometry analysis (MS) was performed in the positive ion mode (PI) and for each antibiotic $[\mathrm{M}+\mathrm{H}]^{+1}$ was selected as precursor ion. It was operated in multiple reaction monitoring mode (MRM). Moreover, for each compound, two MRM transitions were monitored that the most abundant fragment ion was used for quantification and the other one used for identification. A dwell time of $100 \mathrm{~ms}$ per ion pair was used for all antibiotics. The resolution on both analyzers were unit. A summary of individual mass parameters is presented in Table 3. The chromatograms for MRM which well-separated by the Zorbax-eclipse XDB-C18 column are presented in Additional file 1: Fig. S3.

\section{Statistical method using response surface methodology- central composite design (CCD)}

Response surface methodology (RSM) was applied to develop and optimize the processes that are influenced by

Table 2 The gradient elution of mobile phase

\begin{tabular}{lllll}
\hline Step & Total Time $(\mathrm{min})$ & Flow Rate $(\mu \mathrm{l} / \mathrm{min})$ & $\mathrm{A}(\%)$ & $\mathrm{B}(\%)$ \\
\hline 0 & 0.00 & 800 & 95.0 & 5.0 \\
1 & 1.00 & 800 & 95.0 & 5.0 \\
2 & 5.00 & 800 & 12.0 & 88.0 \\
3 & 12.00 & 800 & 0.0 & 100.0 \\
4 & 20.00 & 800 & 95.0 & 5.0 \\
\hline
\end{tabular}

many variables and their interactions. RSM based on Central Composite design (CCD), which is one of the most common used design was applied to optimize simultaneously three independent variables. Then it was followed by desirability function (DF) to suggest an optimized model [27]. In this purpose, Design_ Expert 7.0.0 (version 7.0.0, Stat-Ease Inc., Minneapolis, MN, USA), was used to generate the experimental matrix and then to evaluate the results [27].

Since, the extraction process is one of the important steps in pharmaceutical analysis including antibiotics and has effects on antibiotics recoveries. Optimization of the extraction process and a careful selection of experimental conditions is crucial. To improve the extraction efficiency, three independent variables $\mathrm{pH}$ (X1), the volume of elution solvent (X2) and the amount of $\mathrm{Na}_{4} \mathrm{EDTA}$ (X3) in three levels (low, basal and high) in coded value $(-1,0,+1)$ and the star points of +1.68 and -1.68 as $(+\alpha$ and $-\alpha)$ were evaluated respectively. Independent variables in maximum and minimum levels were depicted in Table 4. The arrangement of experiments and their responses of all antibiotics are presented in Additional file 1: Table S1.

In ANOVA tables, a $P$-value less than 0.05 $(P<0.05)$ indicates the statistical significance of effects at $95 \%$ confidence interval. According to a second-order polynomial model and to minimize the effect of uncontrolled variables, 20 experiments were designed randomly by Central Composite Design (CCD) and carried out.

\section{Results and discussion}

\section{Optimization of extraction parameters by CCD}

Based on previous knowledge from the literature, three significant variables, $\mathrm{pH}$, the volume of elution solvent and the amount of $\mathrm{Na}_{4} \mathrm{EDTA}$ in the range of 3-8, 2$6 \mathrm{~mL}$ and $25-75 \mathrm{mg}$, were investigated. For this purpose, $100 \mathrm{~mL}$ ultrapure water samples were spiked by $80 \mathrm{ng} / \mathrm{L}$ of a mixture of antibiotics and then they were extracted by SPE process, which is described in section 2.4, in proposed conditions by CCD.

After doing CCD based-experiments, the quadratic polynomial models were generated from the experimental data (Additional file 1: Table S11). The significance of the models equations was assessed by analysis of variance and checked by F-test which is shown in ANOVA tables (Additional file 1: Tables S2-S10) [28, 29]. The regression coefficients $\left(R^{2}\right)$, lack of fit, adjusted $R^{2}$ and predicted $R^{2}$ for all target antibiotics were evaluated and presented in Additional file 1: Table S11. The results of two $\beta$ - lactam antibiotics, amoxicillin and penicillin, were presented and discussed here. 
Table 3 The optimum MRM conditions and retention time (RT) for antibiotics by HPLC/MS/MS

\begin{tabular}{lllllllll}
\hline Raw & Antibiotic & Time $(\mathrm{msec})$ & Precursor ion $(\mathrm{m} / \mathrm{z})$ & $\mathrm{Q} 3$ & DP/EP/CEP/CE/CXP & Q3 & DP/EP/CEP/CE/CXP & RT(min) \\
\hline 1 & Azithromycin-d3 & 100 & $753.076[\mathrm{M}+\mathrm{H}]+$ & 83.2 & $71 / 7.5 / 64 / 75 / 4$ & 158.2 & $71 / 7.5 / 64 / 51 / 4$ & 5.096 \\
2 & Amoxicillin & 100 & $366.32[\mathrm{M}+\mathrm{H}]+$ & 114.3 & $21 / 5 / 36 / 29 / 4$ & 134.2 & $21 / 5 / 36 / 43 / 4$ & 1.86 \\
3 & Cefixime & 100 & $454.699[\mathrm{M}+\mathrm{H}]+$ & 126.2 & $41 / 6 / 42 / 45 / 4$ & 285.3 & $41 / 6 / 42 / 23 / 6$ & 5.22 \\
4 & Ceftriaxone & 100 & $555.909[\mathrm{M}+\mathrm{H}]+$ & 125.1 & $31 / 6 / 44 / 77 / 4$ & 167.2 & $31 / 6 / 44 / 35 / 4$ & 4.91 \\
5 & Ciprofloxacin & 100 & $332.498[\mathrm{M}+\mathrm{H}]+$ & 314.500 & $46 / 5.5 / 36 / 37 / 6$ & 231.400 & $46 / 5.5 / 36 / 47 / 6$ & 4.96 \\
5 & Ciprofloxacin-d8 & 100 & $340.578[\mathrm{M}+\mathrm{H}]+$ & 322.500 & $46 / 7 / 38 / 35 / 6$ & 235.300 & $46 / 7 / 38 / 51 / 6$ & 4.9602 \\
6 & Erythromycin & 100 & $735.086[\mathrm{M}+\mathrm{H}]+$ & 158.200 & $46 / 6.5 / 64 / 39 / 4$ & 83.100 & $46 / 6.5 / 64 / 73 / 4$ & 5.4607 \\
7 & Metronidazole & 100 & $172.103[\mathrm{M}+\mathrm{H}]+$ & 128.100 & $31 / 4.5 / 20 / 19 / 4$ & 82.1 & $31 / 4.5 / 20 / 33 / 4$ & 4.5051 \\
8 & Penicillin-G & 100 & $335.480[\mathrm{M}+\mathrm{H}]+$ & 91.100 & $56 / 7.5 / 38 / 65 / 4$ & 128.200 & $56 / 7.5 / 38 / 37 / 4$ & 5.14 \\
9 & Cephalexin & 100 & $348.497[\mathrm{M}+\mathrm{H}]+$ & 158.1 & $21 / 4.5 / 34 / 19 / 4$ & 106.200 & $21 / 4.5 / 34 / 37 / 4$ & 4.91 \\
10 & Cefuroxime-d3 & 100 & $427.888[\mathrm{M}+\mathrm{H}]+$ & 324.700 & $71 / 6.5 / 36 / 23 / 6$ & 143.200 & $81 / 6 / 38 / 41 / 4$ & 9.55 \\
11 & Metronidazole-d4 & 100 & $176.199[\mathrm{M}+\mathrm{H}]+$ & 128.100 & $31 / 4.5 / 16 / 21 / 4$ & 82.100 & $31 / 4.5 / 16 / 33 / 4$ & 4.45 \\
12 & Azithromycin & 100 & $750.048[\mathrm{M}+\mathrm{H}]+$ & 158.300 & $76 / 7.5 / 62 / 51 / 4$ & 83.100 & $76 / 7.5 / 62 / 75 / 4$ & 5.0967 \\
\hline
\end{tabular}

Regarding to Additional file 1: Table S11, the adjusted $\mathrm{R}^{2}$ for amoxicillin and penicillin were 0.9696 and 0.9798 respectively, which indicated that more than $90 \%$ of the variability within the response data will be explained by model. In general, the higher the R-squared, the better the model fits of data. Adequate Precision for both responses, amoxicillin and penicillin, were 35.550 and 28.906 respectively. The signal to noise ratio (response/deviation) was measured by adequate precision. A ratio greater than four is desirable. The ratios of 35.550 and 28.906 indicate the adequate signal to noise, so the model can be used to navigate the design space.

Reproducibility of the model is measured by the coefficient of variation (C.V). The value of C.V less than $10 \%$ indicate that the model is reproducible [29]. the values of C.V for Amoxicillin and Penicillin were 3.69 and 6.99 respectively, that indicates the model is reproducible sufficientlly.

Lack of fit in both ANOVA tables was nonsignificant with $p$-value of 0.3419 and 0.5758 for amoxicillin and penicillin respectively which Nonsignificant lack of fit means the model is fit due to the pure error [30, 31]. Lack of fit of the models for all antibiotics were non-significant (Additional file 1:
Tables S2-S10). Diagnostic plots including Perturbation plot (A), normal probability plot (B), Internally studentized (C) and plot of residuals versus predicted values (D) were analysed for both responses and depicted in Additional file 1: Figs. S1 and S2.

As can be seen in Additional file 1: Figs. S1B and $\mathrm{S} 2 \mathrm{~B}$, in the normal probability plot for both antibiotics, residuals (the points) lie down close to the straight line, which indicate that the residuals follow a regular distribution $[29,31]$. Furthermore, the Perturbation plots show the relative significance of factors on extraction recoveries of antibiotics and provides a lay-out view of response surface plots. The steepest slope of curvatures indicate the sensitivity of recovery to $\mathrm{pH}$ (Additional file 1: Figs. S1A and S2A) [29-32]. The plot of residual versus predicted value Additional file 1: Figs. S1C and S2C, represent the deviation of actual values versus predicted values. Moreover, They show that residuals were distributed randomly around zero and there wasn't any outlier. It implies that there isn't any point with more than three-time of standard deviation from the mean. The actual and predicted Extraction recoveries (ER\%) of amoxicillin and penicillin are shown in Additional file 1: Figs. S1D

Table 4 Independent variables in maximum and minimum levels and the star point for CCD

\begin{tabular}{|c|c|c|c|c|c|}
\hline \multirow[t]{2}{*}{ Variables } & \multicolumn{3}{|l|}{ Levels } & \multicolumn{2}{|c|}{ Star point $a=1.68$} \\
\hline & $\operatorname{Low}(-1)$ & Central (0) & $\operatorname{High}(+1)$ & $-a$ & $+a$ \\
\hline$\left(\mathrm{X}_{1}\right) \mathrm{pH}$ & 3 & 5.5 & 8 & 1.2 & 9.7 \\
\hline$\left(\mathrm{X}_{2}\right)$ Solvent Volume $(\mathrm{mL})$ & 2 & 4 & 6 & 0.63 & 7.36 \\
\hline$\left(X_{3}\right)$ Na4 EDTA $(m g)$ & 25 & 50 & 75 & 7.955 & 92.04 \\
\hline
\end{tabular}


and S2D respectively. Considering that the adjusted $R^{2}$ and predicted $R^{2}$ should be within 0.2 of each other, in this model adjusted $R^{2}$ and predicted $R^{2}$ for ER\% of amoxicillin and ER\% of Penicillin were (0.9696 and 0.9328$)$ and (0.9798 and 0.9133) respectively. So good agreement between the adjusted $R^{2}$ value and each predicted $R^{2}$ value indicated a proper adjustment between the observed and predicted values [31, 33]. Model Equations in terms of coaded factor are depicted in Additional file 1: Table S11.

\section{The interaction effects of independent variables on the extraction recoveries}

Response surface plots depict the extraction efficiencies are a function of two independent variables. The response surface plot for ER\% of amoxicillin shows that the increasing in the volume of solvent from 2 to $6 \mathrm{~mL}$ led to a marginal increasing of amoxicillin recoveries in both the low and high levels of $\mathrm{Na}_{4}$ EDTA (Fig. 1). Figure 2a represents that if $\mathrm{pH}$ value was kept constant at 5.5, increasing in the amount of Na4EDTA and the volume of extraction solvent led to decreasing of the extraction recovery (ER \%) of penicillin up to $64 \%$. While, in $\mathrm{pH}=3$, with increasing of the amount of $\mathrm{Na}_{4} \mathrm{EDTA}$ and the volume of elution solvent, the highest extraction recovery (ER\%) of penicillin was obtained up to $80 \%$ (Fig. 2b and c). The response surface plot for ER\% of penicillin Fig. $2 \mathrm{~b}$, shows that at low levels of $\mathrm{pH}$, the increasing in the volume of the solvent resulted in a rapid enhancement of ER\% for Penicillin. Figure 2c shows that at low and high levels of $\mathrm{Na}_{4} \mathrm{EDTA}$, with increasing in $\mathrm{pH}$ levels from 2 to 8 , ER\% of Penicillin has a rapid decline which can be explained by $\mathrm{pKa}$ values of compounds. These surface plots apparently indicated that $\mathrm{pH}$ was the main factor which affects the extraction recovery of antibiotics.

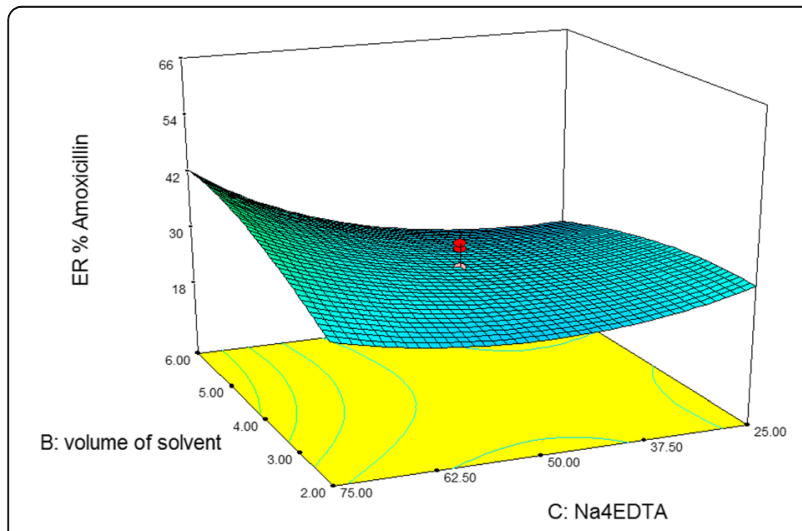

Fig. 1 Response surface plot for ER\% Amoxicillin

\section{Effect of $\mathrm{pH}$}

The $\mathrm{pH}$ of the samples plays an important role in the extraction recovery of antibiotics [25]. It can affect the stability and the interaction between the analytes and the material of sorbent. To study the effects of $\mathrm{pH}$ on extraction efficiency of antibiotics in water matrices, pka values for all compounds should be investigated. Considering that $\beta$-lactams (BLs), macrolides (MLs), fluoroquinolones (FLs), nitro-imidazole antibiotics have acidic or basic functional group, so their ionization is controlled by the $\mathrm{pH}$ of the sample solution [21]. Therefore, regarding acidic substances, acidification of water samples 2 unit under pka values of target antibiotics is recommended to obtain their neutral or acidic form of the analytes. It leads to retention of these target antibiotics in Oasis HLB cartridges $[8,21,34]$. In some previous studies, the best recoveries for antibiotics were obtained in strong acidic condition in the range of 2 to $4[8,9,15,21]$. But in some studies $\mathrm{pH}$ adjustment has not taken into consideration in extraction process [35], whereas $\mathrm{pH}$ adjustment is an important step in extraction efficiency due to different sample $\mathrm{pH}$ and charge of each analyte. In this work, the majority of studied analytes were $\beta$-lactam antibiotics, including penicillins and cephalosporins, which their analysis was difficult in multi-residues methods due to the chemically unstable $\beta$-lactam ring. So that they readily undergo hydrolysis $[5,15,25,36,37]$. That's why, $\beta$-lactam antibiotics have been investigated in a few studies [8].

Additional file 1 Table S1 represents the recoveries of $\beta$-lactam and cephalosporin antibiotics which were obtained more than those reported for erythromycin, azithromycin and ciprofloxacin. It can be explained by $\mathrm{pKa}$ values.

Regarding $\mathrm{pKa}$ values of amoxicillin, penicillin, cefixime, cephalexin and ceftriaxone (Table 1), at acidic and natural conditions they are in cationic and zwitterion form, so they were well-retained on the polymeric Oasis HLB column due to their polarity. According previous studies, better recoveries were obtained by Oasis HLB cartridges concern to hydrophilic-lipophilic character of the sorbent $[9,10,38]$. So in present work, higher recoveries for almost all target antibiotics were obtained by acidification of samples prior to extraction process with Oasis HLB cartridges $[8,9,11,39-45]$. In fact, because of the chemical composition of Oasis HLB, which consists of lipophilic divinylbenzene units and the hydrophilic $\mathrm{N}$-vinylpyrrolidone units, the efficient extraction of organic contaminants in a wide range of $\mathrm{pH}$ (from $\mathrm{pH} 1$ to 14) can be obtained. [8] Therefore, the recovery experiments and the analysis of samples were carried out in this conditions. 


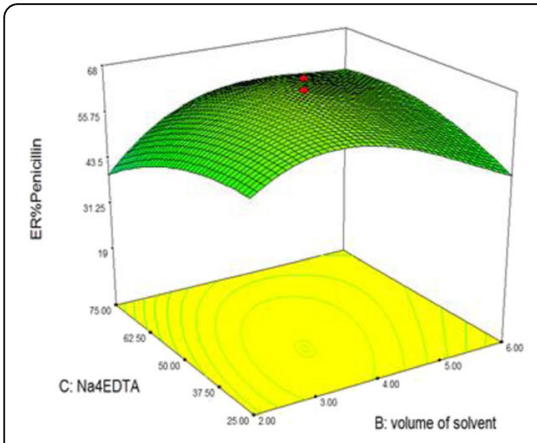

$\mathbf{a}$

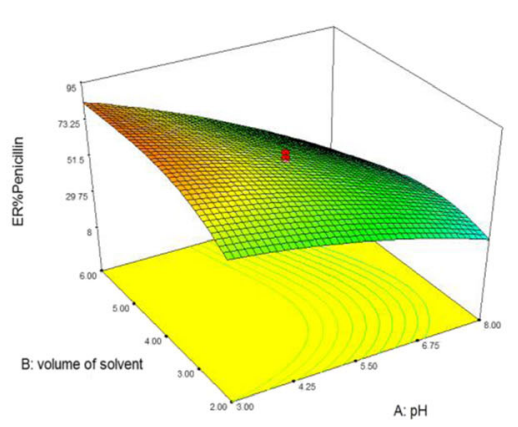

b

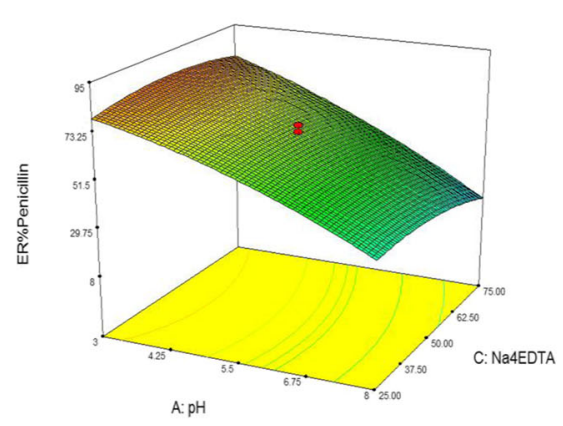

c

Fig. 2 Response surface plot for ER\% Penicillin in, pH value of 5.5, (Na4EDTA vs. Volume of solvent) (a). Response surface plot for ER\% Penicillin in $\mathbf{N a}_{\mathbf{4}}$ EDTA $=\mathbf{5 0} \mathbf{~ m g}$ ( $\mathrm{pH}$ vs. Volume of solvent) (b). Response surface plot for ER\% Penicillin in the volume of solvent $=\mathbf{4} \mathbf{m L}$ (pH vs. Na4EDTA) (c)

ANOVA tables show $\mathrm{pH}$ was the most significant model terms in extraction recovery of amoxicillin, penicillin, cefixime, cephalexin, ceftriaxone, with $p$ value of $<0.0001,<0.0001,<0.0001,0.0002,<$ 0.0001 respectively (Additional file 1: Tables S2, S3, S5, S7 and S9). Considering to pka values, penicillins and cephalosporins were in a cationic form in acidic condition 2 units under their $\mathrm{pk}_{\mathrm{a}}$ values. Hence, they were well retained on the polymeric Oasis HLB cartridge $[14,21]$. In addition, regards to Table 6 , the recoveries for amoxicillin, penicillin, cephalexin, ceftriaxone were obtained up to $90 \%$, except for cefixime which were obtained up to $55 \%$ in different water matrices. Macrolide antibiotics consist of a basic dimethylamine [-N (CH3)2] group, which is able to take a proton [21] and according to their $\mathrm{pk}_{\mathrm{a}}$ values, they are basic compounds, so that their retention on reversed phased cartridges was not $\mathrm{pH}$ dependent in the range of 3-7 [21, 46]. Therefore, $\mathrm{pH}$ was not significant model term in extraction efficiency of azithromycin and erythromycin with $p$ value of 0.3218 and 0.1326 respectively. Regarding to the $\mathrm{pk}_{\mathrm{a}}$ values of azithromycin (8.74) and erythromycin (8.88) (Table 1) [47], they can be recovered in higher values of $\mathrm{pH}$. Hence, the recoveries of azithromycin and erythromycin in the recovery study were obtained in treated water, ground water and surface water (52, 55 and 47\%) and (56, 44 and 42\%) respectively (Table 6).

Regarding fluoroquinolones, ciprofloxacin is one of the most widely used fluoroquinolone antibiotics all over the world [48]. They have an amino group (piperazinyl) in the heterocyclic ring and have two dissociation constants [8]. The reported $\mathrm{pKa}$ values of ciprofloxacin were 5.76 (strangest acidic) and 8.68 (strangest basic) $[49,50]$. They are in their zwitterion form in neutral condition and in cationic form in acidic condition so they are well retained on the polymeric Oasis HLB column [21]. The recoveries of ciprofloxacin in treated water, ground water and surface water were 75,88 and $87 \%$ respectively (Table $6)$. For compounds with relatively high $\mathrm{pKa}$ values such as metronidazole, the improvement in recovery is not significant under sample acidification [9]. Moreover, the result of ANOVA test for metronidazole shows that $\mathrm{pH}$ model term was not statistically significant $(p$-value $=0.1134)$ in extraction efficiency of metronidazole (Additional file 1: Table S8).

\section{Effect of eluent volume}

In order to desorb the adsorbates as fully as possible in SPE columns and to maximize the sensitivity of the analysis, to choose appropriate eluent is essential. According to the fact that SPE extraction is based on the interaction between adsorbate and adsorbent, extraction efficiency is highly dependent on the polarity of the eluent [9]. Acetonitrile and methanol were the most frequently used eluents in the extraction recovery of antibiotics from HLB cartridges $[8,39]$. Although methanol can cause the potential for analyte degradation $[44,51]$ it can provide better chromatographic peaks. If chromatographic run is fast enough, degradation effects can be negligible $[44,51]$. So methanol was used as elution solvent in this work. The volume of elution solvent was the statistically significant model term in extraction efficiency of four antibiotics included cefixime, metronidazole, ceftriaxone and azithromycin with $p$ value of $<0.0001,0.0113,0.0002$ and 0.0094 respectively. It is noteworthy that, large volume of elution solvent more than $6 \mathrm{ml}$ takes more time in evaporation step in SPE process, degradation of $\beta$ - lactams is quite likely in the presence of methanol under the gentle nitrogen stream due to instability of $\beta$ - lactam 
ring. To avoid analytes degradation and shorten the time of evaporation, the extracts were evaporated under a gentle nitrogen stream in $35{ }^{\circ} \mathrm{C}$ in a water bath which shortened the time of evaporation up to $1.5 \mathrm{~h}$.

\section{Effect of $\mathrm{Na}_{4}$ EDTA}

Due to the fact that the antibiotics can potentially bind residual metals which are present in the sample matrix and glassware, the extraction recoveries decrease. By adding chelating agent, including $\mathrm{Na}_{4}$ EDTA, metal ions are bounded to the chelating agent and make the extraction efficiency increase $[10,52,53]$. The effect of $\mathrm{Na}_{4}$ EDTA ranged from 25 to $75 \mathrm{mg} / \mathrm{L}$ on extraction efficiency was evaluated. Regarding to ANOVA tables (Additional file 1: Tables S2-S10), the value of $\mathrm{Na}_{4}$ EDTA was not a significant model term in extraction efficiency except for amoxicillin with p-value of 0.0007 . On the other hand, simultaneous increase of Na4EDTA and the volume of elution solvent lead to decreasing of extraction efficiency (Fig. 4a). Fluoroquinolones and macrolides have a high tendency to complex with metal ions which resulting in lower extraction recoveries. So, to achieve higher extraction efficiency, the addition of strong enough chelating agent is crucial [8].

\section{Optimization of CCD by desirability factor for extraction procedure}

The optimization profile in Expert Design 7.0.0 software was used to optimize the extraction process. The desirability is measured by specifying the desirability factor (DF) for each dependent variable or responses. It can take values from 0 (undesirable) to 1 (very desirable). It would be maximized if the selected criteria were optimized efficiently. The criteria for optimization were $\mathrm{pH}, \mathrm{Na}_{4} \mathrm{EDTA}$ and the volume of extraction solvent. Desirability function (D) is expressed by the equation follows:

$$
\mathrm{D}=\left[\mathrm{d}_{1}{ }^{\mathrm{p} 2} \mathrm{xd}_{2}{ }^{\mathrm{p} 2} \mathrm{xd}_{3}{ }^{\mathrm{p} 2} \mathrm{x} \ldots \ldots \mathrm{d}_{\mathrm{n}}{ }^{\mathrm{pn}} \mathrm{x}\right]^{1 / \mathrm{n}}
$$

Where $\mathrm{p}^{\mathrm{i}}$ is the weight of the response, $\mathrm{n}$ the number of responses and $d_{i}$ is the individual desirability function of each response [29, 31, 32]. The criteria can be weighted from 0.1 to 10 which lower than 1 gives less importance to the goal and greater than 1 gives more importance. Five suggested models with desirability up to $0.84 \%$ were presented in Additional file 1: Table S12. In method validation procedure, the validity of experiments in optimum operating conditions was investigated, and the results were close to which obtained from the optimized model using a CCD.

\section{Method validation}

Quantification was based on linear regression calibration curves using the internal standard approach to minimize or correct the matrix effects. The method validation was assessed in terms of linearity; accuracy and precision, instrumental detection limit (IDL), method detection limit (MDL), method quantification limit (MQL) and repeatability which the results were presented in Tables 5 and 6 . Accuracy was assessed by further doing experiments using spiking natural water samples. Recoveries were determined by spiking treated water, ground water and river water, in triplicate, at a concentration of $100 \mathrm{ng} / \mathrm{L}$ of a mixture of antibiotics and extracted under the optimum conditions, which the recoveries were presented in Table 6. Two standard mixtures were spiked, the first one contained penicillins and cephalosporins in HPLC grade water and the other one contained azithromycin, erythromycin and metronidazole in methanol [8]. Recoveries obtained for all antibiotics ranged from 50 to

Table 5 Calibration equation, instrumental detection limits (IDLs), linearity and repeatability (run-to-run analysis) determined for target antibiotics

\begin{tabular}{|c|c|c|c|c|c|}
\hline No. & Antibiotic & Calibration equation & Regression coefficient & $\begin{array}{l}\text { IDL }\left(n g . L^{-1}\right)^{a} \\
\text { (injected) }\end{array}$ & $\begin{array}{l}\text { Repeatability \%RSD } \\
(n=5)\end{array}$ \\
\hline 1 & Metronidazole & $y=0.172 x+0.324$ & 0.992 & 1 & 13.4 \\
\hline 2 & Ceftriaxone & $y=5.32 e-4 x-4.7 e-4$ & 0.984 & 2.5 & 11.6 \\
\hline 3 & Penicillin & $y=0.0067 X-0.058$ & 0.991 & 2.5 & 8.1 \\
\hline 4 & Amoxicillin & $y=0.028 x-6.8 e-4$ & 0.956 & 1 & 5.3 \\
\hline 5 & Azithromycin & $y=0.052 x-0.32$ & 0.974 & 1 & 7.8 \\
\hline 6 & Cephalexin & $y=0.003 X-0.024$ & 0.991 & 2.5 & 5.1 \\
\hline 7 & Ciprofloxacin & $y=0.013 X-0.042$ & 0.993 & 2.5 & 8.4 \\
\hline 8 & Erythromycin & $y=0.015 x+0.36$ & 0.987 & 1 & 6.7 \\
\hline 9 & Cefixime & $y=5.8 e-4 x+0.02$ & 0.990 & 2.5 & 6.3 \\
\hline
\end{tabular}

\footnotetext{
${ }^{\mathrm{a}} I D L$ Instrumental Detection Limit
} 


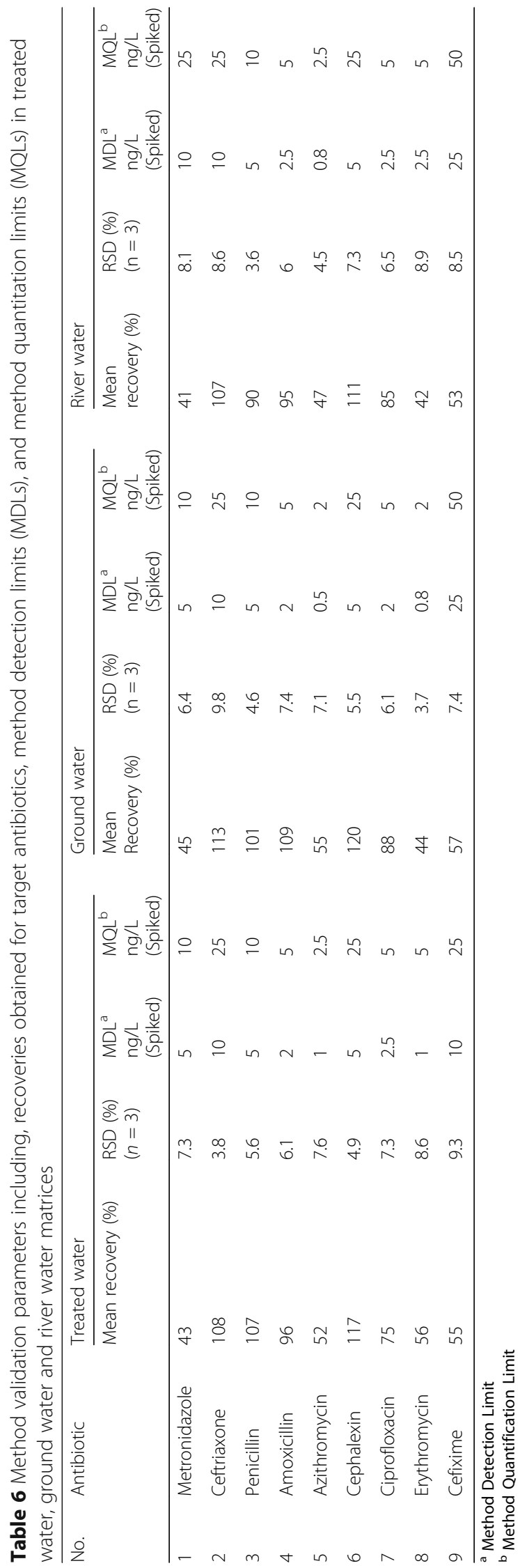


$110 \%$ except metronidazole which was obtained in treated, ground and river water $43 \%, 45 \%$ and $41 \%$ respectively. Furthermore, erythromycin in treated water, azithromycin and erythromycin in river water samples showed low recoveries ( $44 \%, 47 \%$ and $42 \%$ respectively). The low recoveries of some macrolide antibiotics and metronidazole can be described by instability in acidic condition through SPE process. Regarding some cephalosporins, low recoveries in all water matrices is due to their chemical structure and undergoing the hydrolysis [21]. In present work, the reported MDLs and MQLs for penicillins and cephalosporins are comparable to those were obtained in previous literatures $[8,14,54]$.

RSD values were determined for all antibiotics in natural water samples, which were less than $10 \%$, which was a good signal of precision. RSD values were in the range of $3.8-9.3 \%$ for treated water, (3.7-9.8\%) for ground water and (3.6-8.9\%) for river water. Regarding standard deviation values calculated for each antibiotic (RSD, $n=3$ ), repeatability of the proposed method is high. The method detection limit (MDL) and method quantification limit (MQL) were calculated with a signal to noise of 3 and 10 respectively. But finally we checked it with our findings in practice. According Table 6, MDL values varied in the range of $1-10 \mathrm{ng} / \mathrm{L}$ in treated water, $0.8-10 \mathrm{ng} / \mathrm{L}$ in the ground water and $0.8-25 \mathrm{ng} / \mathrm{L}$ in river water. MQL values for treated water were ranging from $2.5-25 \mathrm{ng} / \mathrm{L}$, ground water $2-50 \mathrm{ng} / \mathrm{L}$ and river water $2.5-50 \mathrm{ng} / \mathrm{L}$. Repeatability was assessed by five consecutive injection of a $500 \mathrm{ng} / \mathrm{L}$ calibration curve standard. The RSD values were achieved below $10 \%$ with exception for metronidazole and ceftriaxone.

\section{Application to natural water matrices}

The developed method was successfully applied to treated water, ground water and river water samples which were collected from Tehran water resources, including water wells and drinking water treatment plants and two rivers passing through residential zones in Tehran during July to September in 2016. Sixty treated water, 39 ground water and 12 river water samples were collected and analyzed. The results are summarized in Table 7. None of the antibiotics were detected in treated water and ground water samples but seven out of nine antibiotics were detected in Kan River water and Firozabad Ditch. Ceftriaxone and metronidazole were not detected in any of the samples. The concentrations of antibiotics varied from $11.76 \mathrm{ng} / \mathrm{L}$ for ciprofloxacin in Kan River samples to $404.96 \mathrm{ng} / \mathrm{L}$ for azithromycin in Firozabad Ditch.

The highest concentration of antibiotics was discovered in Firozabad Ditch which is receiving the effluent of Ekbatan wastewater treatment plant located in Ekbatan area in west of Tehran. Furthermore, cefixime and cephalexin were detected at the highest median concentration of 71.91 and $93.19 \mathrm{ng} / \mathrm{L}$ in Kan River samples respectively. While azithromycin and ciprofloxacin were detected at the highest median concentration of $439.35 \mathrm{ng} / \mathrm{L}$ and $212.83 \mathrm{ng} / \mathrm{L}$ respectively.

The discovered antibiotics in the Kan River were attributed to the discharges of untreated wastewaters from the unauthorized constructions along the river and releasing the untreated wastewater directly into the river. It is not surprising that azithromycin and ciprofloxacin were detected at the highest median concentrations. The presence of antibiotics belonging to macrolides and fluoroquinolones (erythromycin, azithromycin and ciprofloxacin) had also been reported in surface water in previous works [40, 55-57]. Although many researchers detected different classes of antibiotics in wastewater treatment plant influent and effluent as well as hospital wastewater [8, 58, 59], a few works reported our target antibiotics in surface water. Gros et al. (2006)

Table 7 Detected antibiotics in $\mathrm{ng} / \mathrm{L}$, in Treated water, in Ground water and surface water including, Kan River and Firozabad Ditch

\begin{tabular}{llllll}
\hline No. & Antibiotic & Treated water $(n=30)$ & Ground water $(n=39)$ & Kan River water $(n=6)$ & Firozabad Ditch $(n=6)$ \\
\hline 1 & Metronidazole & N.D & N.D & N.D \\
2 & Ceftriaxone & N.D & N.D & N.D & $<$ MQL $^{\mathrm{b}}$ \\
3 & Penicillin & N.D & N.D & $50.94 \pm 17.68$ & $21.05 \pm 12.53$ \\
4 & Amoxicillin & N.D & N.D & $18.00 \pm 11.03$ & $31.14 \pm 11.67$ \\
5 & Azithromycin & N.D & N.D & $52.66 \pm 0.14$ & $404.96 \pm 175.46$ \\
6 & Cephalexin & N.D & N.D & $96.03 \pm 87.29$ & $94.51 \pm 55.35$ \\
7 & Ciprofloxacin & N.D & N.D & $11.76 \pm 7.42$ & $308.65 \pm 253.58$ \\
8 & Erythromycin & N.D & N.D & $16.61 \pm 1.03$ & $28.055 \pm 11.05$ \\
9 & Cefixime & N.D & N.D & $71.89 \pm 73.62$ & $79.09 \pm 49.47$ \\
\hline
\end{tabular}

a Not detected

${ }^{\mathrm{b}}$ Below method quantification limit 
found erythromycin and azithromycin in surface water in the range of $<\mathrm{MDL}-30 \mathrm{ng} / \mathrm{L}$ and $<\mathrm{MDL}-20 \mathrm{ng} / \mathrm{L}$ respectively [11], though at lower levels than those reported herein. Hao et al., (2011) detected azithromycin and erythromycin in the highest concentration of 90.80 and $2246 \mathrm{ng} / \mathrm{L}$ in the Red River delta of northern Vietnam [60]. Christian et al., (2003) detected azithromycin, erythromycin and ciprofloxacin in the range of $2-3 \mathrm{ng} / \mathrm{L}$, 4-190 $\mathrm{ng} / \mathrm{L}$ and $9 \mathrm{ng} / \mathrm{L}$ in the aquatic environment of the Land of North Rhine-Westphalia in Germany [61]. The presence of erythromycin was quantified with $0.62 \mu \mathrm{g} / \mathrm{l}$ in the small river Lutter in Bielefeld, Germany [62]. The presence of erythromycin, azithromycin and ciprofloxacin were detected in the range of $50.38-174.73 \mathrm{ng} / \mathrm{L}, 14.73-$ $71.76 \mathrm{ng} / \mathrm{L}$ and $8.32-28.02 \mathrm{ng} / \mathrm{L}$ respectively in Llobreg River basin, NE Spain [26]. Regarding to previous literatures, azithromycin and erythromycin and ciprofloxacin are frequently detected antibiotics in surface water $[26,61$, 63]. Penicillin and Amoxicillin were reported in wastewater samples and surface water frequently but studies including cephalosporins are still infrequent. In present work, cephalosporin antibiotics including cefixime and cephalexin were detected in the range of $<\mathrm{MQL}$ $136.31 \mathrm{ng} / \mathrm{L}$ and $<\mathrm{MQL}-177.60 \mathrm{ng} / \mathrm{L}$ in both investigated river waters, respectively. That high concentrations of antibiotics in Kan River and Firozabad Ditch were found in dry season and the other reason is probable due to low rainfall and untreated wastewater discharges.

In Fig. 3, the total ion current (TIC) chromatograms from a standard mixture at a concentration of $50 \mathrm{ng} / \mathrm{mL}$ is depicted and the chromatograms for real samples containing some of the compounds analyzed are displayed in Fig. 4.

\section{Conclusion}

An optimized SPE-HPLC-MS/MS method developed to analyze multi-residues of different classes of antibiotics, including $\beta$-lactam (amoxicillin and penicillin G), cephalosporin (ceftriaxone, Cefixime, and cephalexin), macrolides (azithromycin and erythromycin), fluoroquinolone (ciprofloxacin) and Nitro-imidazole (metronidazole) in groundwater and treated water as well as surface water. $\mathrm{PH}$, the amount of $\mathrm{Na}_{4} \mathrm{EDTA}$ and the volume of elution solvent were simultaneously optimized by applying response surface methodology - central composite design to explore the relationship between variables and responses (extraction recoveries of antibiotics) in the extraction process. D-optimal function was applied to suggest the predicted models and report desirability factors (DF) for suggested models. After doing CCD- based experiments, the results showed that the acidification

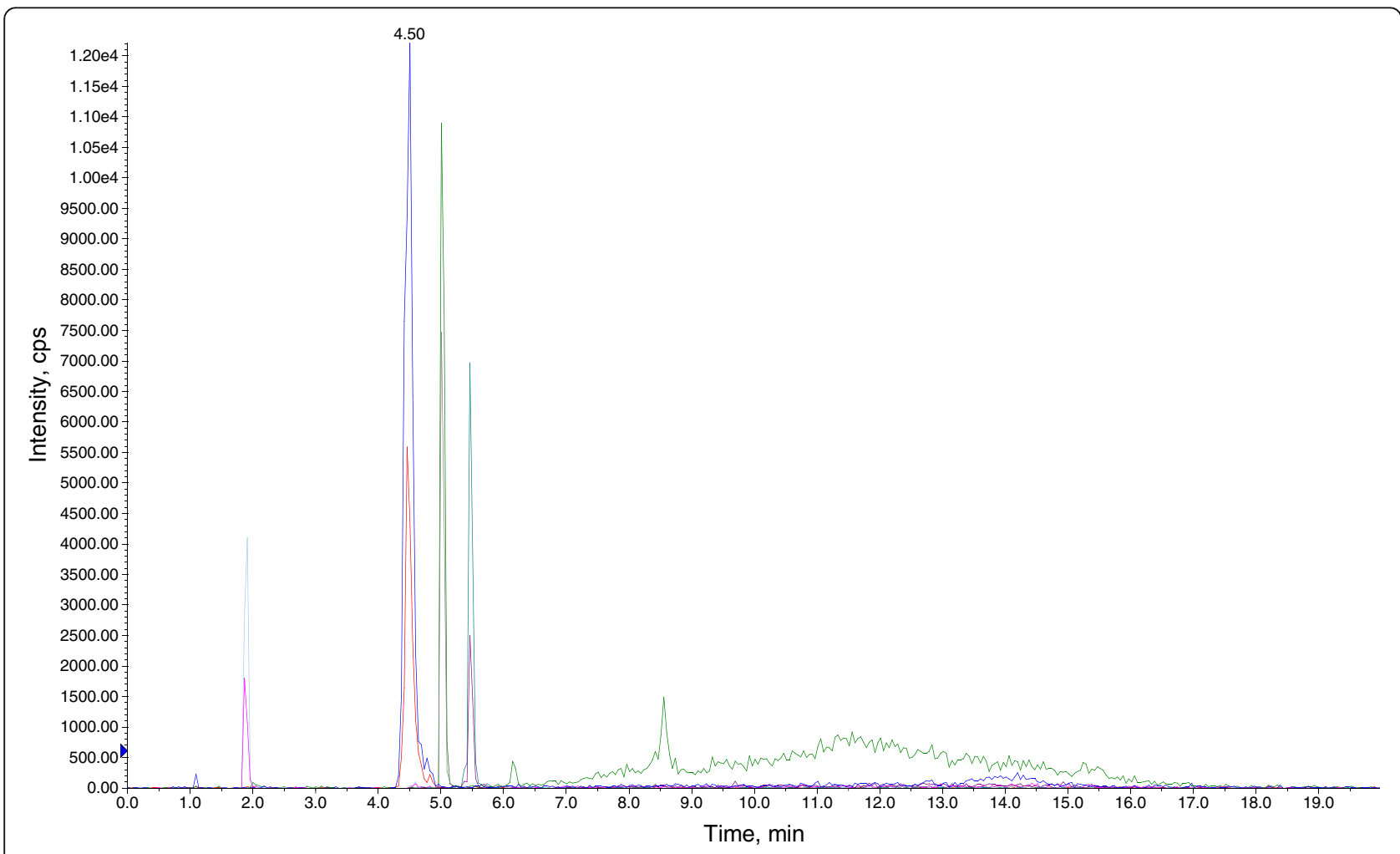

Fig. 3 Total ion chromatograms (TIC) of a $50 \mathrm{ng} / \mathrm{mL}$ standard mixture of target antibiotics 


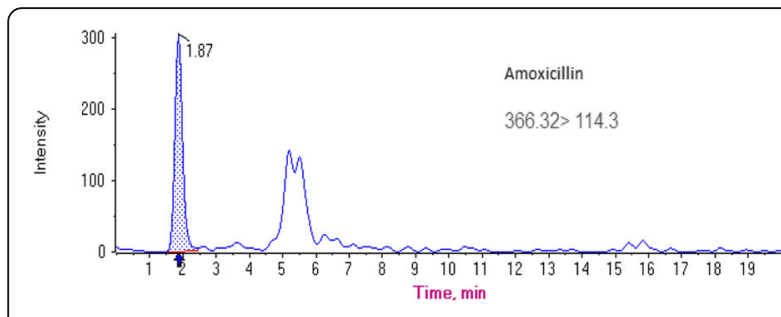

a

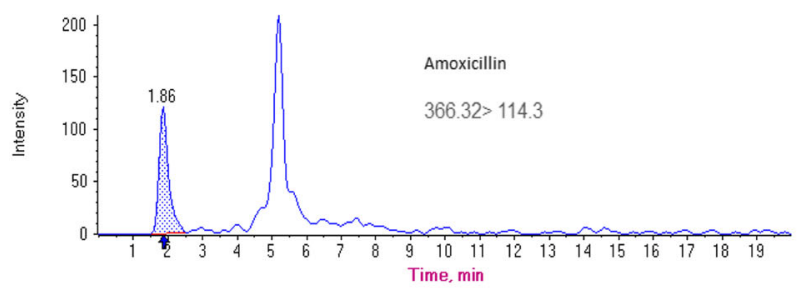

c

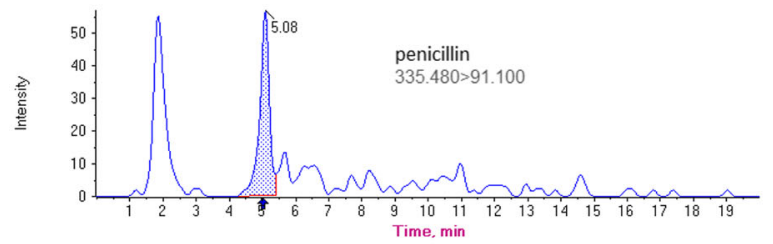

e

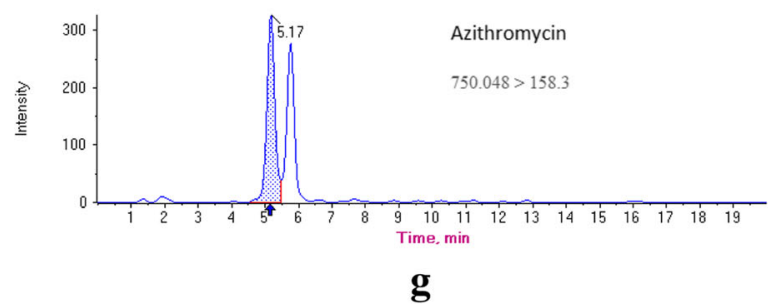

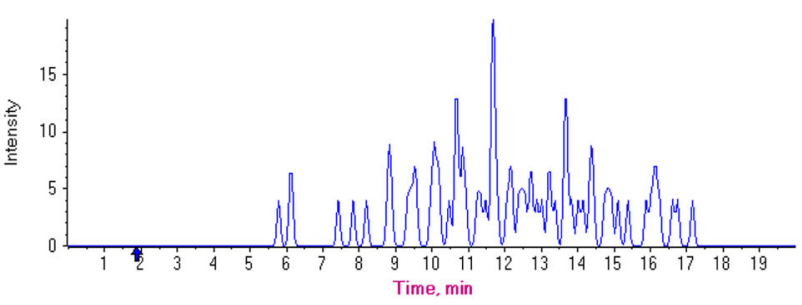

b

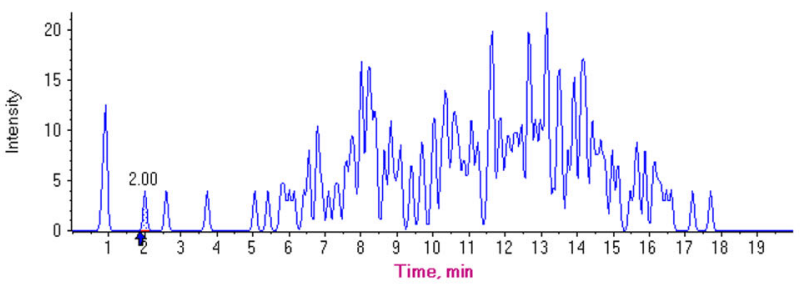

d
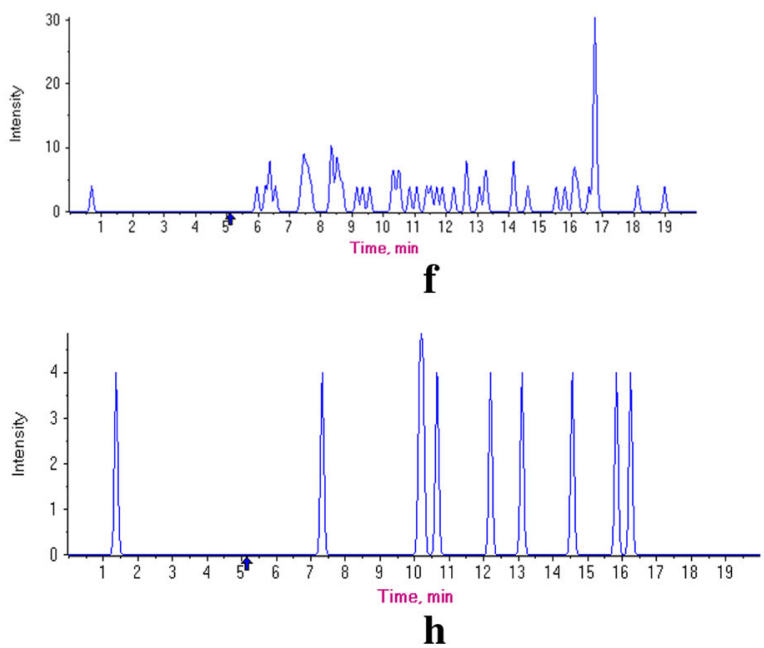

Fig. 4 Chromatograms for $\beta$ - lactam antibiotics and one macrolide antibiotic found positive in two river water samples: a Amoxicillin at 31 ng/L in Firozabad stream water sample; b chromatogram of corresponding blank of amoxicillin (RT = 1.87 min), and $\mathbf{c} 18$ ng/L in Kan River sample, $\mathbf{d}$ chromatogram of corresponding blank of amoxicillin (RT = $1.87 \mathrm{~min}$ ), e penicillin at $51 \mathrm{ng} / \mathrm{L}$ in Kan River sample; $\mathbf{f}$ chromatogram of corresponding blank of penicillin (RT = $5.08 \mathrm{~min}$ ); $\mathbf{g}$ Azithromycin at $404 \mathrm{ng} / \mathrm{L}$ in Firozabad stream water; $\mathbf{h}$ chromatogram of corresponding blank of Azithromycin (RT $=5.17 \mathrm{~min}$ )

of water samples to $\mathrm{pH} 3$ improved the retention of $\beta$-lactam and cephalosporin antibiotics on HLB cartridges for all water matrices which the results were in accordance with the pka value of each compound. The optimum volume of elution solvent and the optimum amount of $\mathrm{Na}_{4}$ EDTA was obtained $6 \mathrm{ml}$ and $75 \mathrm{mg}$ in (100 $\mathrm{ml}$ of water sample) respectively. Analysis of variance was carried out for nine antibiotics and $\mathrm{pH}$ was the most significant model term in model equations for all antibiotics expect azithromycin, erythromycin and metronidazole which were in agreement with their pKa values. The volume of elution solvent was significant model terms for cefixime, ceftriaxone and metronidazole model equations. While, the amount of $\mathrm{Na}_{4}$ EDTA was the significant model term in the amoxicillin model equation. The developed method resulted in method detection limit in the range of low $\mathrm{ng} / \mathrm{L}$ for all water matrices and provided a reliable analytical performance within multi-residues method for $\beta$-lactam antibiotics including penicillin and cephalosporins. The developed method was applied to treated, ground and river water samples. Seven out of nine antibiotics were detected in Kan River and Firozabad Ditch water samples, although none of them were detected in treated water and ground water samples. 


\section{Additional file}

Additional file 1: It was provided in a format of DOC (Microsoft Word) including Central composite arrangement and responses in Table S.1 and ANOVA Tables S.2-10, The quadratic polynomial models and statistical parameters in Table S.11, Five proposed models for analysis of investigated antibiotics by multiresidues method in Table S.12, d iagnostic plots for ER\% of amoxicillin in Fig.S.1, diagnostic plots for ER\% of penicillin in Fig.S.2 and the chromatograms for MRM by the Zorbaxeclipse XDB-C18 column in Fig.S.3 were depicted. (DOCX 6167 kb)

\section{Abbreviations}

CCD: Central Composite Design; CE: Collision energy; CV: Coefficient variation; CXP: Cell exit potential; DF: Desirability factor; DP: Declustering potential; EDTA: Ethylenediaminetetraacetic Acid; ESI: Electrospray ionization; HLB: Hydrophilic-Lipophilic Balance; HPLC: High Performance liquid chromatography; IS: Internal standard; LC-MS/MS: Liquid Chromatography Tandem Mass Spectrometry; LOD: Limit of Detection; LOQ: Limit of Quantification; MDL: Method detection limit; MQL: Method quantification limit; RSM: Response Surface Methodology

\section{Acknowledgments}

This study is part of a PhD dissertation and supported by Tehran University of Medical Sciences. We would like to show our gratitude to the Mr. Mostafa Roosta is acknowledged for his technical assistance with HPLC and 3200 QTRAP mass spectrometers. Central food and drug laboratory, Food \& Drug Administration is acknowledged for supporting laboratory equipment. Department of Water and Wastewater Quality Control Laboratory of Tehran is acknowledged for providing treated water and ground water samples.

\section{Funding}

This work has been supported by Tehran University of Medical Sciences through the Ph.D. dissertation [Grant No: 92-02-46-23,340].

\section{Availability of data and materials}

The dataset supporting the conclusions of this article is included within the article (and its additional file). All the necessary data have been given in the paper. If other investigators need our data for their works, they can contact with first author through the email.

\section{Authors' contributions}

$\mathrm{RM}$ is a PhD student who conceived of the research question, involved in experimental design, performed analytical and statistical experiments, and drafted the manuscript. AM and MY supervised the study. SN, MG, EJ and SS were advisors of the study. HSB assisted in performing the analytical experiments. All of authors contributed in all steps of work and read and approved the final manuscript.

\section{Ethics approval and consent to participate}

Not applicable.

\section{Consent for publication}

Not applicable.

\section{Competing interests}

The authors declare they have no competing interests.

\section{Publisher's Note}

Springer Nature remains neutral with regard to jurisdictional claims in published maps and institutional affiliations.

\section{Author details}

${ }^{1}$ Center for Water Quality Research (CWQR), Institute for Environmental Research (IER), Tehran University of Medical Sciences, 8th floor, Gol Building, North Karegar St., Enghelab Sq, Tehran, Iran. ²Department of Environmental Health Engineering, School of Public Health, Tehran University of Medical Sciences, Tehran, Iran. ${ }^{3}$ Center for Air Pollution Research (CAPR), Institute for Environmental Research (IER), Tehran University of Medical Sciences, Tehran, Iran. ${ }^{4}$ Department of Environmental Health Engineering, School of Public
Health, Iran University of Medical Sciences, Tehran, Iran. ${ }^{5}$ Water and Wastewater Company, Department of Water and Wastewater Quality Control Laboratory, Tehran, Iran. ${ }^{6}$ Food and Drug Reference Control Laboratories Center, Food and Drug Organization, Ministry of Health \& Medical Education, Tehran, Iran.

Received: 23 January 2017 Accepted: 19 September 2017

Published online: 17 October 2017

\section{References}

1. Verlicchi P, Galletti A, Petrovic M, Barceló D. Hospital effluents as a source of emerging pollutants: An overview of micropollutants and sustainable treatment options. Journal of Hydrology. 2010;389(3-4):416-28. https://doi. org/10.1016/j.jhydrol.2010.06.005.

2. Kümmerer K. Drugs in the environment: emission of drugs, diagnostic aids and disinfectants into wastewater by hospitals in relation to other sources a review. Chemosphere. 2001;45(6-7):957-69. doi:10.1016/s00456535(01)00144-8.

3. Petrović $M$, Gonzalez S, Barceló D. Analysis and removal of emerging contaminants in wastewater and drinking water. TrAC Trends Anal Chem. 2003;22(10):685-96.

4. de Jesus GV, Almeida CM, Rodrigues A, Ferreira E, Benoliel MJ, Cardoso W. Occurrence of pharmaceuticals in a water supply system and related human health risk assessment. Water Res. 2015:72:199-208.

5. Hernando M, Rodríguez A, Vaquero J, Fernández-Alba A, García E. Environmental risk assessment of emerging pollutants in water: Approaches under horizontal and vertical EU legislation. Crit Rev Environ Sci Technol. 2011;41(7):699-731.

6. Kümmerer K. Antibiotics in the aquatic environment-a review-part II. Chemosphere. 2009;75(4):435-41.

7. Magnér J, Filipovic M, Alsberg T. Application of a novel solid-phaseextraction sampler and ultra-performance liquid chromatography quadrupole-time-of-flight mass spectrometry for determination of pharmaceutical residues in surface sea water. Chemosphere. 2010;80(11): 1255-60. https://doi.org/10.1016/j.chemosphere.2010.06.065.

8. Gros M, Rodríguez-Mozaz S, Barceló D. Rapid analysis of multiclass antibiotic residues and some of their metabolites in hospital, urban wastewater and river water by ultra-high-performance liquid chromatography coupled to quadrupole-linear ion trap tandem mass spectrometry. J Chromatogr A. 2013;1292:173-88

9. Zhou L-J, Ying G-G, Liu S, Zhao J-L, Chen F, Zhang R-Q, et al. Simultaneous determination of human and veterinary antibiotics in various environmental matrices by rapid resolution liquid chromatography-electrospray ionization tandem mass spectrometry. J Chromatogr A. 2012;1244:123-38.

10. Gros M, Rodríguez-Mozaz S, Barceló D. Fast and comprehensive multiresidue analysis of a broad range of human and veterinary pharmaceuticals and some of their metabolites in surface and treated waters by ultra-highperformance liquid chromatography coupled to quadrupole-linear ion trap tandem mass spectrometry. J Chromatogr A. 2012;1248:104-21.

11. Gros M, Petrović M, Barceló D. Development of a multi-residue analytical methodology based on liquid chromatography-tandem mass spectrometry (LC-MS/MS) for screening and trace level determination of pharmaceuticals in surface and wastewaters. Talanta. 2006;70(4):678-90. https://doi.org/10. 1016/j.talanta.2006.05.024.

12. Safari $G H$, Hoseini $M$, Seyedsalehi M, Kamani $H$, Jaafari J, Mahvi AH. Photocatalytic degradation of tetracycline using nanosized titanium dioxide in aqueous solution. Int J Environ Sci Technol. 2015;12(2):603-16. doi:10. 1007/s13762-014-0706-9.

13. Rahmani K, Faramarzi MA, Mahvi AH, Gholami M, Esrafili A, Forootanfar $H$, et al. Elimination and detoxification of sulfathiazole and sulfamethoxazole assisted by laccase immobilized on porous silica beads. International Biodeterioration \& Biodegradation. 2015;97:107-14.

14. Cha JM, Yang S, Carlson KH. Trace determination of $\beta$-lactam antibiotics in surface water and urban wastewater using liquid chromatography combined with electrospray tandem mass spectrometry. J Chromatogr A 2006;1115(1-2):46-57. doi:10.1016/j.chroma.2006.02.086.

15. Lindberg $R$, Jarnheimer P-Å, Olsen B, Johansson M, Tysklind M. Determination of antibiotic substances in hospital sewage water using solid phase extraction and liquid chromatography/mass spectrometry and group analogue internal standards. Chemosphere. 2004;57(10):1479-88. 
16. Hibbert DB. Experimental design in chromatography: A tutorial review. J Chromatogr B. 2012;910:2-13. doi:10.1016/j.jchromb.2012.01.020.

17. Jančić B, Medenica M, Ivanović D, Malenović A. Experimental Design in Chromatographic Analysis of Pramipexole and Its Impurities, Acta Chimica Slovenica. 2007;54(1):49-54.

18. Bruno F, Curini R, Corcia AD, Nazzari M, Samperi R. Solid-Phase Extraction Followed by Liquid Chromatography-Mass Spectrometry for Trace Determination of $\beta$-Lactam Antibiotics in Bovine Milk. J Agric Food Chem. 2001;49(7):3463-70. doi:10.1021/jf010046r.

19. Pozo OJ, Guerrero C, Sancho JV, Ibáñez M, Pitarch E, Hogendoorn E, et al. Efficient approach for the reliable quantification and confirmation of antibiotics in water using on-line solid-phase extraction liquid chromatography/tandem mass spectrometry. J Chromatogr A. 2006; 1103(1):83-93

20. Watkinson A, Murby E, Kolpin D, Costanzo S. The occurrence of antibiotics in an urban watershed: from wastewater to drinking water. Sci Total Environ. 2009:407(8):2711-23.

21. Seifrtová M, Nováková L, Lino C, Pena A, Solich P. An overview of analytical methodologies for the determination of antibiotics in environmental waters. Anal Chim Acta. 2009;649(2):158-79.

22. Golet EM, Alder AC, Hartmann A, Ternes TA, Giger W. Trace Determination of Fluoroquinolone Antibacterial Agents in Urban Wastewater by SolidPhase Extraction and Liquid Chromatography with Fluorescence Detection. Anal Chem. 2001;73(15):3632-8. doi:10.1021/ac0015265.

23. Ye Z, Weinberg HS, Meyer MT. Trace analysis of trimethoprim and sulfonamide, macrolide, quinolone, and tetracycline antibiotics in chlorinated drinking water using liquid chromatography electrospray tandem mass spectrometry. Anal Chem. 2007;79(3):1135-44.

24. Tong L, Li P, Wang Y, Zhu K. Analysis of veterinary antibiotic residues in swine wastewater and environmental water samples using optimized SPELC/MS/MS. Chemosphere. 2009;74(8):1090-7.

25. Dorival-García N, Zafra-Gómez A, Cantarero S, Navalón A, Vílchez JL. Simultaneous determination of 13 quinolone antibiotic derivatives in wastewater samples using solid-phase extraction and ultra performance liquid chromatography-tandem mass spectrometry. Microchemical Journal. 2013;106:323-33. https://doi.org/10.1016/j.microc.2012.09.002.

26. López-Serna R, Pérez S, Ginebreda A, Petrović M, Barceló D. Fully automated determination of 74 pharmaceuticals in environmental and waste waters by online solid phase extraction-liquid chromatography-electrospray-tandem mass spectrometry. Talanta. 2010;83(2):410-24.

27. Stat-Ease I. Design Expert software, Educational Version 7.0.3. Wiley Publishing; 2007

28. Rezaee R, Maleki A, Jafari A, Mazloomi S, Zandsalimi Y, Mahvi AH. Application of response surface methodology for optimization of natural organic matter degradation by UV/H $<$ inf $>2</$ inf $>0<$ inf $>2</$ inf $>$ advanced oxidation process. Journal of Environmental Health Science and Engineering. 2014;12(1) doi:10.1186/2052-336X-12-67.

29. Ghafari S, Aziz HA, Isa MH, Zinatizadeh AA. Application of response surface methodology (RSM) to optimize coagulation-flocculation treatment of leachate using poly-aluminum chloride (PAC) and alum. Journal of Hazardous Materials. 2009;163(2):650-6. https://doi.org/10.1016/j.jhazmat. 2008.07.090

30. Ashrafi S, Nasseri S, Alimohammadi M, Mahvi A, Faramarzi M. Optimization of the enzymatic elimination of flumequine by laccase-mediated system using response surface methodology. Desalin Water Treat. 2016;57(31):14478-87.

31. Ahmadi M, Vahabzadeh F, Bonakdarpour B, Mofarrah E, Mehranian M. Application of the central composite design and response surface methodology to the advanced treatment of olive oil processing wastewater using Fenton's peroxidation. Journal of Hazardous Materials. 2005;123(1): 187-95. https://doi.org/10.1016/j.jhazmat.2005.03.042.

32. Sudha T, Shanmugasundram P. Simultaneous Optimization of the Resolution and Analysis time in RP-HPLC Method for Abacavir and Lamivudine using Derringer's desirability function. International Journal of PharmTech Research. 2014:6(3):1040-8.

33. Gunst RF. Response surface methodology: process and product optimization using designed experiments. Taylor \& Francis Group; 1996.

34. Lindberg RH, Östman M, Olofsson U, Grabic R, Fick J. Occurrence and behaviour of 105 active pharmaceutical ingredients in sewage waters of a municipal sewer collection system. Water Res. 2014;58:221-9.

35. Cahill JD, Furlong ET, Burkhardt MR, Kolpin D, Anderson LG. Determination of pharmaceutical compounds in surface- and ground-water samples by solid-phase extraction and high-performance liquid chromatographyelectrospray ionization mass spectrometry. Journal of Chromatography A. 2004;1041(1-2):171-80. https://doi.org/10.1016/j.chroma.2004.04.005.

36. Díaz-Cruz MS, Barceló D. LC-MS2 trace analysis of antimicrobials in water sediment and soil. TrAC Trends in Analytical Chemistry. 2005;24(7):645-57. https://doi.org/10.1016/j.trac.2005.05.005.

37. Roosta M, Ghaedi M, Daneshfar A, Sahraei R. Experimental design based response surface methodology optimization of ultrasonic assisted adsorption of safaranin $\mathrm{O}$ by tin sulfide nanoparticle loaded on activated carbon. Spectrochim Acta A Mol Biomol Spectrosc. 2014;122:223-31.

38. Nageswara Rao R, Venkateswarlu N, Narsimha R. Determination of antibiotics in aquatic environment by solid-phase extraction followed by liquid chromatography-electrospray ionization mass spectrometry. Journal of Chromatography A. 2008;1187(1):151-64. https://doi.org/10.1016/j. chroma.2008.02.021.

39. Díaz-Cruz MS, Barceló D. Determination of antimicrobial residues and metabolites in the aquatic environment by liquid chromatography tandem mass spectrometry. Anal Bioanal Chem. 2006;386(4):973-85.

40. Ibáñez M, Guerrero C, Sancho JV, Hernández F. Screening of antibiotics in surface and wastewater samples by ultra-high-pressure liquid chromatography coupled to hybrid quadrupole time-of-flight mass spectrometry. J Chromatogr A. 2009;1216(12):2529-39.

41. Lindberg RH, Wennberg P, Johansson Ml, Tysklind M, Andersson BA. Screening of human antibiotic substances and determination of weekly mass flows in five sewage treatment plants in Sweden. Environmental science \& technology. 2005;39(10):3421-9.

42. Bueno MJM, Agüera A, Hernando MD, Gómez MJ, Fernández-Alba AR. Evaluation of various liquid chromatography-quadrupole-linear ion trapmass spectrometry operation modes applied to the analysis of organic pollutants in wastewaters. J Chromatogr A. 2009:1216(32):5995-6002.

43. Shaner RL, Allegood JC, Park H, Wang E, Kelly S, Haynes CA, et al. Quantitative analysis of sphingolipids for lipidomics using triple quadrupole and quadrupole linear ion trap mass spectrometers. J Lipid Res. 2009;50(8): 1692-707.

44. Kantiani L, Farre M, Sibum M, Postigo C, López de Alda M, Barcelo D. Fully automated analysis of $\beta$-lactams in bovine milk by online solid phase extraction-liquid chromatography-electrospray-tandem mass spectrometry. Anal Chem. 2009;81(11):4285-95.

45. Eichhorn P, Aga DS. Identification of a photooxygenation product of chlortetracycline in hog lagoons using LC/ESI-ion trap-MS and LC/ESI-timeof-flight-MS. Anal Chem. 2004;76(20):6002-11.

46. Yang S, Cha J, Carlson K. Trace analysis and occurrence of anhydroerythromycin and tylosin in influent and effluent wastewater by liquid chromatography combined with electrospray tandem mass spectrometry. Anal Bioanal Chem. 2006:385(3):623-36.

47. Wishart DS, Knox C, Guo AC, Shrivastava S, Hassanali M, Stothard P, et al DrugBank: a comprehensive resource for in silico drug discovery and exploration. Nucleic Acids Res. 2006;34(Database issue):D668-72. doi:10. 1093/nar/gkj067.

48. Wagil M, Kumirska J, Stolte S, Puckowski A, Maszkowska J, Stepnowski P, et al. Development of sensitive and reliable LC-MS/MS methods for the determination of three fluoroquinolones in water and fish tissue samples and preliminary environmental risk assessment of their presence in two rivers in northern Poland. Science of The Total Environment. 2014;493:100613. https://doi.org/10.1016/j.scitotenv.2014.06.082.

49. Renew JE, Huang $\mathrm{C}-\mathrm{H}$. Simultaneous determination of fluoroquinolone, sulfonamide, and trimethoprim antibiotics in wastewater using tandem solid phase extraction and liquid chromatography-electrospray mass spectrometry. J Chromatogr A. 2004;1042(1):113-21.

50. Turiel E, Bordin G, Rodríguez AR. Trace enrichment of (fluoro) quinolone antibiotics in surface waters by solid-phase extraction and their determination by liquid chromatography-ultraviolet detection. J Chromatogr A 2003;1008(2):145-155.

51. Lara FJ, del Olmo-Iruela M, Cruces-Blanco C, Quesada-Molina C, GarcíaCampaña AM. Advances in the determination of $\beta$-lactam antibiotics by liquid chromatography. TrAC Trends Anal Chem. 2012;38:52-66.

52. Hernández F, Sancho JV, Ibáñez M, Guerrero C. Antibiotic residue determination in environmental waters by LC-MS. TrAC Trends Anal Chem. 2007;26(6):466-85

53. Yang S, Cha J, Carlson K. Simultaneous extraction and analysis of 11 tetracycline and sulfonamide antibiotics in influent and effluent domestic 
wastewater by solid-phase extraction and liquid chromatographyelectrospray ionization tandem mass spectrometry. J Chromatogr A. 2005: 1097(1):40-53.

54. Gros M, Petrović M, Barceló D. Multi-residue analytical methods using LCtandem MS for the determination of pharmaceuticals in environmental and wastewater samples: a review. Anal Bioanal Chem. 2006;386(4):941-52

55. Nödler K, Licha T, Bester K, Sauter M. Development of a multi-residue analytical method, based on liquid chromatography-tandem mass spectrometry, for the simultaneous determination of 46 micro-contaminants in aqueous samples. Journal of Chromatography A. 2010;1217(42):6511-21. https://doi.org/10.1016/j.chroma.2010.08.048.

56. Yang J-F, Ying G-G, Zhao J-L, Tao R, Su H-C, Chen F. Simultaneous determination of four classes of antibiotics in sediments of the Pearl Rivers using RRLC-MS/MS. Science of The Total Environment. 2010;408(16):342432. https://doi.org/10.1016/iscitotenv.2010.03.049.

57. Zhou JL, Maskaoui K, Lufadeju A. Optimization of antibiotic analysis in water by solid-phase extraction and high performance liquid chromatographymass spectrometry/mass spectrometry. Anal Chim Acta. 2012;731:32-9.

58. Lin AY-C, Yu T-H, Lin C-F. Pharmaceutical contamination in residential, industrial, and agricultural waste streams: Risk to aqueous environments in Taiwan. Chemosphere. 2008;74(1):131-41. https://doi.org/10.1016/j. chemosphere.2008.08.027.

59. Verlicchi P, Al Aukidy M, Galletti A, Petrovic M, Barceló D. Hospital effluent: investigation of the concentrations and distribution of pharmaceuticals and environmental risk assessment. Sci Total Environ. 2012;430:109-18.

60. Hoa PTP, Managaki S, Nakada N, Takada H, Shimizu A, Anh DH, et al. Antibiotic contamination and occurrence of antibiotic-resistant bacteria in aquatic environments of northern Vietnam. Sci Total Environ. 2011;409(15): 2894-901.

61. Christian T, Schneider RJ, Färber HA, Skutlarek D, Meyer MT, Goldbach HE. Determination of antibiotic residues in manure, soil, and surface waters. Acta Hydrochim Hydrobiol. 2003;31(1):36-44

62. Hirsch R, Ternes TA, Haberer K, Mehlich A, Ballwanz F, Kratz K-L. Determination of antibiotics in different water compartments via liquid chromatography-electrospray tandem mass spectrometry. J Chromatogr A. 1998;815(2):213-23.

63. Golet EM, Alder AC, Giger W. Environmental exposure and risk assessment of fluoroquinolone antibacterial agents in wastewater and river water of the Glatt Valley Watershed, Switzerland. Environmental science \& technology. 2002;36(17):3645-51.

\section{Submit your next manuscript to BioMed Central and we will help you at every step:}

- We accept pre-submission inquiries

- Our selector tool helps you to find the most relevant journal

- We provide round the clock customer support

- Convenient online submission

- Thorough peer review

- Inclusion in PubMed and all major indexing services

- Maximum visibility for your research

Submit your manuscript at www biomedcentral.com/submit

) Biomed Central 